Fabio Nelson Rodríguez Díaz*

\title{
Aprender y enseñar el diseño en tiempos de Uber: plataformas multilaterales para la educación ${ }^{1}$
}

\section{Cómo citar:}

Rodríguez, F. (2019). Aprender y enseñar el diseño en tiempos de Uber: plataformas multilaterales para la educación. Designia, 7(1), 139-145.

*Diseñador Gráfico y Magíster en Museología y Gestión del Patrimonio, egresado de la Universidad Nacional de Colombia. Profesor de Tiempo Completo en la Universidad de Boyacá. Tunja, Boyacá, Colombia. E-mail: fnrodriguez@uniboyaca.edu.co ORCID: http://orcid.org/0000-0003-0652-4107

\section{Palabras clave:}

Aprendizaje, diseño, educación, enseñanza, plataformas multilaterales.

Key words:

Learning, design, education,

teaching, platform business model.

Recibido: 15/12/2019

Aceptado: 2/03/2020

El internet ha permeado y transformado la cotidianidad humana. Aunque corta, su historia ha sido vertiginosa y en apenas unos 30 años pasó de utilizarse para formas de comunicación sencillas, a convertirse en imprescindible en la vida social, la economía y, por supuesto, en la educación, con la que ha tenido una relación estrecha desde su mismo nacimiento. Por supuesto, el comercio también aprovechó la oportunidad de ofrecer sus productos y servicios a nuevos mercados; así, las plataformas multilaterales aprovecharon 
la fragmentación y la dificultad de los modelos de negocio tradicionales para adaptarse a esta nueva realidad, y conectaron a los productores y los clientes. En los últimos años, la educación ha hecho lo propio poniendo a disposición de un gran público contenidos educativos atractivos, a través de plataformas que conectan a docentes con estudiantes. La propuesta de valor de estos nuevos negocios es atender las frustraciones que los clientes acumulan, por eso en este texto se abordarán las problemáticas relacionadas con los costos, la presencialidad, la masificación versus la personalización, la pertinencia de los contenidos educativos y la didáctica de los sistemas educativos presenciales y tradicionales. Así mismo, se plantearán los inconvenientes relacionados con la formación de competencias blandas, las condiciones laborales de los docentes y el riesgo de que los contenidos educativos sean determinados por las dinámicas de la oferta y la demanda.

\section{Abstract:}

The internet has permeated and transformed human everyday life. Although short, its history has been dizzying and in just over 30 years it went from being used for simple forms of communication, to becoming essential in social life, economy and, of course, education, with which it has had a relationship narrow from birth. Of course, commerce also took the opportunity to offer its products and services to new markets; Thus, multilateral platforms took advantage of the fragmentation and difficulty of traditional business models to adapt to this new reality, and connected producers and customers. In recent years, education has done the same by making attractive educational content available to a large audience, through platforms that connect teachers with students. The value proposition of these new businesses is to address the frustrations that customers accumulate, so this text will address the issues related to costs, presentiality, overcrowding versus personalization, the relevance of educational content and the didactics of face-to-face and traditional educational systems. Likewise, the problems related to the training of soft skills, the working conditions of teachers and the risk that educational content will be determined by the dynamics of supply and demand will be raised. 


\section{Introducción}

La aparición de internet ha transformado de manera radical las comunicaciones y con ello, muchas de las cosas que hacemos en nuestra vida cotidiana. En un principio, apenas se intercambiaban simples mensajes, ideas en foros y correos electrónicos; luego, con la aparición de la World Wide Web la forma de acceder al conocimiento cambió de manera drástica y entonces grandes diccionarios y numerosos tomos de enciclopedias dejaron de ocupar los anaqueles de las bibliotecas para ser reemplazados por un ordenador de escritorio. No pasó mucho tiempo hasta que las mejoras en la velocidad de conexión y de procesamiento de los aparatos convirtieron a la red en algo imprescindible: hoy están casi desaparecidos los directorios telefónicos, no la tienen fácil los periódicos o las revistas y para muchos es impensable hacer una fila para pagar las facturas de los servicios públicos. Hoy internet está en todo y casi todo está en internet.

La educación no es la excepción y de hecho fueron las universidades estadounidenses las primeras instituciones en conectarse, por lo que internet ha tenido fines educativos incluso desde sus mismos inicios. Ya en los noventa, se configuraban las primeras plata- formas para educación online que funcionaban como entornos donde era posible la interacción entre estudiantes y docentes, la presentación de actividades y el seguimiento y evaluación del proceso formativo.

Por otro lado, la posibilidad de generar ingresos a través de la red no fue clara desde sus inicios, pero no tardaría mucho y a mediados de los noventa se abrieron desde las populares tiendas Ebay y Amazon, hasta otras menos famosas. El comercio, entonces, se transformó y con el cambio de siglo muchas personas y empresas encontraron a través de internet interesantes fuentes de ingresos, casi siempre en beneficio de los mismos consumidores a través de los avances en la forma de acceder a los productos y la mejora en la calidad de prestación de los servicios.

Desde el 2006 aparecieron los teléfonos inteligentes y le dieron un fuerte impulso a la masificación del internet, potenciando nuevas maneras de hacer negocios a través de las redes móviles. Para entonces, ya internet contaba con compañías de gran tamaño, pero esa posibilidad de llegar a mercados muy numerosos, sumada a las dificultades para asumir los costos de la fluctuación de la demanda trajo consigo una solución disruptiva: crear plataformas en donde los productos o servicios fueran ofrecidos por terceros a los consumidores. Finalmente, los beneficios económicos se obtendrían cobrando un porcentaje del costo total de la transacción, generalmente a los propietarios de la oferta, pero todas las partes resultan beneficiadas. El modelo se denomina "plataformas multilaterales" y en palabras de Alexander Osterwalder:

Estas plataformas son de valor para un grupo de clientes sólo si el otro grupo de consumidores está también presente. La plataforma crea valor facilitando la interacción entre los diferentes grupos. La plataforma multilateral crece en valor en la medida que atrae más usuarios, un fenómeno conocido como efecto de red. (Osterwalder, 2011:77) 

aprendizaje del diseño

¿Y qué tiene que ver Uber con el aprendizaje y la enseñanza del diseño? Parte de la respuesta está en algo que es general a la educación, pero más evidente en la formación para el trabajo y los programas profesionales: los conflictos entre la masificación y la personalización. Además, en el caso particular del diseño, agregaría las frustraciones en los contenidos de los programas educativos presenciales, dado que a la educación superior le cuesta y le lleva tiempo adaptarse a nuevas demandas del mercado, que en nuestro campo de conocimiento pueden cambiar de forma vertiginosa, sobre todo en cuanto a habilidades técnicas y tecnológicas.

Lo cierto es que las plataformas más exitosas -Uber por ejemplo- han surgido en sectores donde los consumidores han acumulado frustraciones por años. Cabría preguntarnos ¿cuáles son las frustraciones de los clientes respecto a las ofertas tradicionales de educación? ¿cuál es el valor que crean las plataformas multilaterales de educación a sus clientes? y ¿ese valor es suficiente para atraer clientes hacia esas nuevas ofertas?. De un lado, el sector educativo es particularmente frágil, debido a que no tiene fuertes normas

El ejemplo más emblemático de las plataformas multilaterales es la aplicación móvil Uber, debido, entre otras cosas, a la polémica generada ante la resistencia de los gremios, la controversia frente a las legislaciones vigentes y el aplauso de los consumidores, pero no es la única y la verdad es un modelo en auge. Entre las más populares encontramos a AirBnb, Mercadolibre, Linio, Spotify o el mismo YouTube. Estas plataformas representan la economía postindustrial basada en servicios por encima de productos, así como el diseño centrado en el usuario al tiempo que explotan al máximo todas las últimas tecnologías para mejorar la conexión entre usuarios / consumidores con la oferta de servicios y productos. o una conciencia de gremio que pueda defenderse, como si lo han hecho los taxistas de todo el mundo en parte por no considerarse, al menos en muchos países, como un sector económico. Por otro lado, ¿cuál es el valor que encuentran los estudiantes en la educación? ¿reconocimiento, empleabilidad, conocimiento, un título universitario o la formación humana? Y por último, ¿podría un modelo disruptivo de educación entregar ese valor que buscan los usuarios de manera más personalizada, más barata, con más calidad o de forma más rápida? Cabe aclarar que las plataformas multilaterales para educación ya son una realidad y solo en el contexto hispanoamericano ya tenemos ejemplos como Next University, Domestika y Platzi. 
En un mundo hiperconectado y con medios de transporte cada vez más rápidos, cómodos y económicos, creeríamos que la distancia no es un factor determinante a la hora de acceder a una oferta educativa; no obstante, otros factores como la cercanía a los familiares y seres queridos o las condiciones culturales de un destino si pueden influir. Así mismo, el hecho de poder acceder a la oferta en el momento que el estudiante lo considere y no estar supeditado a los docentes, a otros estudiantes o a la misma disponibilidad de los espacios físicos, implica retos para los modelos educativos más tradicionales, contando con un gran número de oportunidades para las plataformas virtuales, que en este caso puede llegar hasta la atención personalizada entre docentes y estudiantes, cuando ocupar un salón de clase sería impensable.

\section{Masificación versus personalización}

Entre la masificación y la personalización está el problema que solucionan de forma disruptiva las plataformas multilaterales, pues los modelos tradicionales de educación deben elegir entre cuidar de forma personal a sus estudiantes mediante un trato individual o masificar los mismos contenidos educativos, pero con la consiguiente frustración al no atender dudas o no hacer evaluaciones específicas, solo por citar un par de posibles problemas. A través de las herramientas de internet es posible llegar a la personalización con costos bajos para sus usuarios.

\section{Pertinencia de los contenidos educativos}

Las plataformas son multilaterales, al igual que la mayoría de contenidos de internet que son "On Demand", lo que implica que los mismos usuarios deciden cómo articulan la oferta, en qué momento 
acceden a ella y en cuando la abandonan. En el caso de la educación esto es particularmente problemático, dado que la inversión - tiempo, dinero, energía, etc. - generará dividendos que solo serán percibidos en el largo plazo - conocimiento, estatus social, capacidad crítica, mejores ingresos económicos, etc. - y pone en una encrucijada tanto a las plataformas, en el momento de programar sus contenidos, como a los estudiantes a la hora de decidir cuales comprar.

La educación a través de las plataformas es entonces particularmente pertinente a las ofertas no formales, en contraste con los programas presenciales tradicionales, pues sus contenidos casi siempre implican habilidades técnicas frente a temas actuales, como, por ejemplo, el uso de alguna aplicación o software de diseño, el dominio de lenguajes de programación o habilidades puntuales en alguna técnica de ilustración o de diseño.

También cabe mencionar que estas ofertas están abiertas a todas las personas y no solo como educación continuada o complementaria, pues, nuevamente, depende del equilibrio entre oferta y demanda y no es un secreto que la masificación de internet, junto a la mejora en la velocidad de transmisión de datos, han hecho que la forma de los mensajes migre del texto a las imágenes y el video, lo que significa un mercado que requiere de personas que construyan esos mensajes y cada vez sean de mejor calidad para atraer a los cibernautas.
Por último, mencionar que en internet no es suficiente con la reputación institucional, pues quienes enseñan deben tener esa reputación ganada en el mismo medio, que para el caso del diseño son las redes sociales generales como Facebook, Twitter, YouTube o Instagram, o comunidades específicas como Behance, 500px y Dribbble, que implican un reto para quien considere enseñar a través de dichas plataformas pues antes debe ser un líder, construir comunidad y reconocer la dinámica de las redes.

\section{Didáctica}

En cuanto a las técnicas y métodos de enseñanza, el contenido "On Demand" permite ajustar los temas a los tiempos e intereses de los estudiantes. Por ejemplo, en una clase en video el estudiante puede repetir una parte tantas veces como lo considere necesario hasta lograr entender una idea. Si no la llegara a entender puede aún pedir explicación personalizada. Además, estas plataformas pueden integrar metodologías como la Gamificación y herramientas como los juegos, el video, las imágenes, los audios, entre otros, con el fin de hacer una experiencia más amena. 


\section{Los inconvenientes}

Aunque las plataformas multilaterales representan una gran innovación y son capaces de generar valor a través de las mejoras que implementan en los servicios educativos gracias al uso intensivo y consecuente de las nuevas tecnologías, no están exentas, como cualquier otra innovación, de tener algunos problemas, retos y transformaciones que no siempre son positivos. Podríamos empezar desde los objetivos más elementales de la educación, del papel del estudiante y del docente como agentes de transformación social. Asimismo, las habilidades necesarias para la resolución de los problemas más apremiantes del mundo, que no permiten respuestas únicas, sino que requieren una mirada holística y un nivel de entendimiento y crítica superior.

Por otro lado, al tercerizar la oferta, las empresas dejan de asumir los costos que implican mantenerla constante para sus usuarios y son los dueños de esa oferta, en este caso los docentes, quienes asumen estos costos. Empezando por los directamente relacionados con la oferta versus la demanda: si como docente ofrezco un curso que no tenga gran acogida, soy yo quien asume los costos de preparación de clase, organización de los contenidos e incluso recursos económicos para la grabación de video o creación de recursos didácticos. Ya desde el punto de vista normativo de cada país, trabajar como independiente puede tener un costo mayor, pues implica el pago de todas las obligaciones sociales que en otros casos los empleadores ayudan a solventar, siendo estos costos fijos que no se reducen a pesar de una reducción en la demanda.

Para terminar, quiero dejar una pregunta ¿en verdad son los estudiantes quienes definen las competencias que deben adquirir? Pues en la medida que la educación tiene un papel de transformación social, la educación se debe pensar en comunidad. El estado, por ejemplo, debe determinar a través de las políticas públicas el modelo de sociedad que quiere y hacerlo evidente en todas las ofertas educativas, no solo las tradicionales o formales y en ese sentido ¿qué tan pertinente es que sean solo los estudiantes, a través de los mecanismos de oferta y demanda, quienes determinen los contenidos a través de la demanda?

\section{REFERENCIAS BIBLIOGRÁFICAS}

Cordero, H. (2004). Educación inclusiva. Revista electrónica Educare. 6. 23-38.

Osterwalder, A. (2010). Business model generation. New Jersey: Willey. 